\title{
Emotional/Educational, Behavioral \& Developmental [EBD] Problems in Children - Nursing Opportunities
}

\section{Anjan Bhattacharya*}

Department of Paediatrics, Apollo Gleneagles Hospital, Kolkata, India

\section{Introduction}

Biopsychosocial Model of multifactorial causation of diseases are increasingly understood by the care providers for children (Figure 1 adopted from Nelsons Textbook of Pediatrics [1,2] below).

Global burden of Emotional/Educational, Behavioral and Developmental [EBD] problems are said to be in the order of 1 in 4 to 1 in 5 children (prevalence rate) [3]

$75 \%$ of all such children present in Primary Care Setting and accounts for $50 \%$ of all Pediatric consultations. Despite being in the privileged gatekeeping position, Primary Care Physicians were found to be only less than $20 \%$ efficient in identifying such problems [3].

Opportunity must be similarly missed by other healthcare providers both in the community setting as well as hospital in-patients and outpatient departments.

Neuro-developmental problems like Autism, ADHD (Attention Deficit Hyperactivity Disorder), DCD (Developmental Coordination Disorders), Dyslexia and Emotional and Psychosocial Disorders like Low Mood, Low Self Esteem, Frozen Watchfulness, Inappropriate Affect need to be spotted and reported early (Early Detection) and addressed expertly promptly (Early Intervention) as we know that delay leads to downward spiral with lasting morbidity through adolescence and adulthood [3].

We know that the School Nurses are better at such a role [4]. But there are disheartening reports on identification and effective prevention for conditions like obesity despite of their involvements [5].

Missed opportunities of reporting EBD concerns must be one of the important determinants of such morbidity. Opportunities may be missed due to -

- Lack of awareness of their existence

- Inadequate learning to aid spotting them

- Inter-observer variations, bias, prejudices

- Brushing off subtle concerns as "may be, I am being silly"

- Lack of trained supervision and vetting skills in health professionals

- Acknowledging that this is a concern and yet not knowing how to go about it

There is enough science for all healthcare providers to take up leadership role in their day to day practices to try to halt the menacing march of these ballooning biopsychosocial problems, should there be clear cut guidelines to act for them.

Planners and Policy Makers have the daunting task of balancing the act of rationing healthcare [6] vis a vis address public health hazards.

Notwithstanding their dilemma, the cost-effectiveness [7] must be justifiable, when measured not only in the terms of an individual but

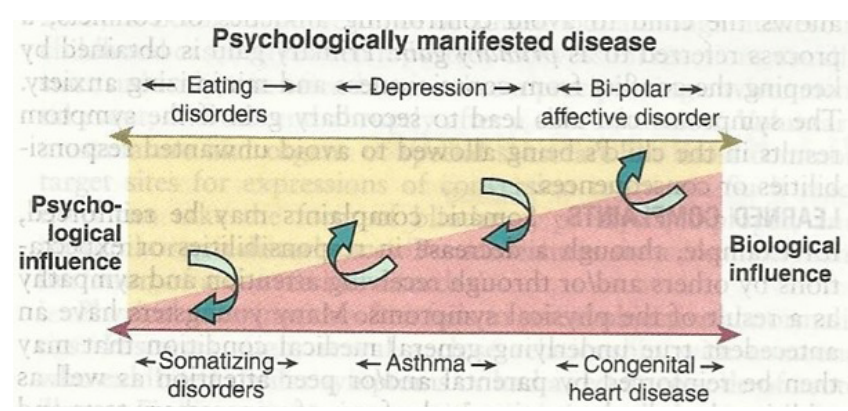

Figure 1: Physically manifested disease.

also in cost reduction through family's health and lost work, if not that of the society at large in the long run.

Hence, Early "Red Flag" Signs must be identified and acted up on. Nurses in all walks of their profession, are in similar privileged role of a "gatekeeper" to pick up 'subclinical' and 'sub threshold' early features and help them nip it in the bud. The basic issues to remember are as follows:

Try to follow standardized and validated Screening Tools wherever possible (see below: a combination of Pediatric Symptom Checklist of Bright Futures (PSC) and M-CHAT of Diana Robins has the potential to be user friendly and good yield in healthcare set ups) (Figure 2a and $2 b)$.

- 'Breaking News' skills [8-10] must be mandatory skill development for all healthcare professionals. I propose OSCE styled competency based learning modules for all healthcare professionals worldwide

- Avoid 'Anticipatory Decision Regret' [11] in care givers through such skill development

- Prompt (same day) referral to Child Development Centre or Early Start Centre [IDEA in the States]

Developmental Pediatricians are appropriate resources to Care Coordinate EBD problems, including prompting a CAMHS (Child and Adolescent Mental Health Services) referral. Care Coordination involving Health, Education and Social Services is an expert domain

*Corresponding author: Anjan Bhattacharya, Department of Paediatrics, Apollo Gleneagles Hospital, Kolkata, India, Tel: 9874797726; E-mail: anjan@gmail.com

Received June 26, 2015; Accepted June 06, 2015; Published June 15, 2015

Citation: Bhattacharya A (2014) Emotional/Educational, Behavioral \& Developmental [EBD] Problems in Children - Nursing Opportunities. Health Care Current Reviews 3: 132. doi: 10.4172/2375-4273.1000132

Copyright: $\odot 2015$ Bhattacharya A. This is an open-access article distributed unde the terms of the Creative Commons Attribution License, which permits unrestricted use, distribution, and reproduction in any medium, provided the original author and source are credited. 
Pediatric Symptom Checklist (PSC)

Emotional and physical health go together in children. Because parents are often the first to notice a problem with their
child's behavior, emotions, or learning, you may help your child get the best care possible by answering these questions. Please indicate which statement best describes your child.

Please mark under the heading that best decribes your child:

1. Complains of aches and pains

2. Spends more time alone

3. Tires easily, has little energy

4. Fidgely, unable to sit still

5. Has trouble with teacher

6. Less interested in school

7. Acts as it driven by a motor

8. Daydreams too much

9. Distracted easily

10. Is afraid of new situations

11. Fee's sad, unhappy

12. Is irritable, angry

13. Feels hopeiess

15. Less interested in friends

16. Fights with other children

17. Absent from school

18. School grades dropping

19. Is down on him- or hersel

20. Visits the doctor with doctor finding nothing wrong

21. Has trouble sleeping

22. Worries a lot

23. Wants to be with you more than before

24. Feels he or she is bad

25. Takes unnecessary risks

26. Gets hurt frequently

27. Seems to be having less fun

28. Acts younger than children his or her age

29. Dose not listen to rules

30. Does not show feelings

31. Does not understand other people's feelings

32. Teases others

33. Blames others for his or her troubles

34. Takes things that do not belong to him or her

35. Refuses to share
14. Has trouble concentrating

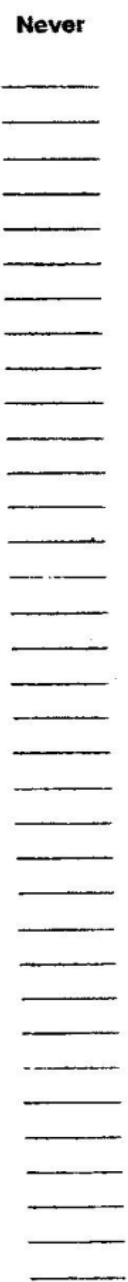

Does your child have any emotional or behavioral problems for which she or he needs help? Are there any services that you would like your child to receive for these problems?

If yes, what services?

Pediatric Symptom Checkist. (From Green M, Palfires JS leditorsl: Bright Futures: Guidelimes of the
Sometimes

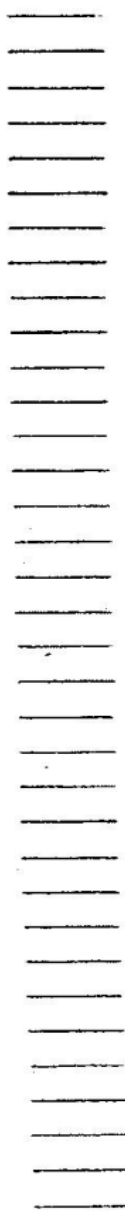

Otten

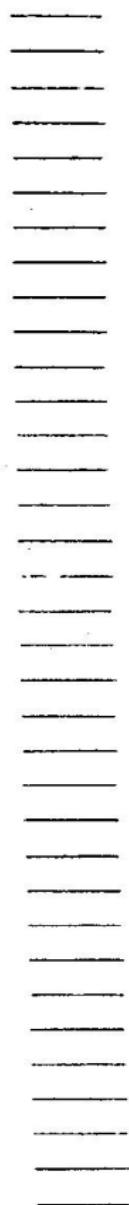

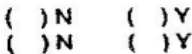
Pediatric Symptom Checklist. (From Green M, Palfrey JS leditors]: Bright Futsteres: Gutdelimes of the
Adolescents, 2nd ed, revised. Arlington, VA, National Center for Education in Maternal and Child Health, 2002.)

Figure 2a: The proposed combined Screening Tool of PSC and M-CHAT.

of a Developmental Pediatrician. Child Development Centers are Resourced Centers for these problems. At the community level a multitude of Early Start Centre under expert professional contribution with overall overview of the Child Development Centre of the catering locality can help prevent snow balling of this health and social menace to the monster that it purports to be.

\section{Care Pathway}

A Universal Care Pathway for "Red Flag" Sub-syndromic and Subthreshhold [12] signs and symptoms of Pediatric EBD problems is proposed as follows:

1. Healthcare professionals receiving training in "Red Flag" signs 
Citation: Bhattacharya A (2014) Emotional/Educational, Behavioral \& Developmental [EBD] Problems in Children - Nursing Opportunities. Health Care Current Reviews 3: 132. doi: 10.4172/2375-4273.1000132

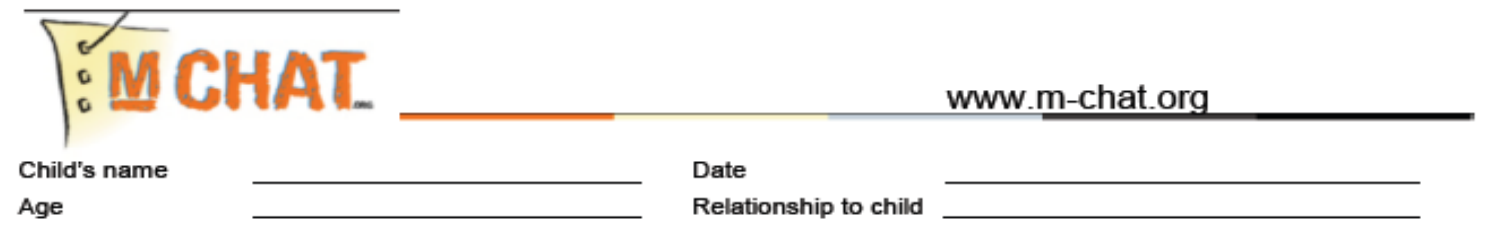

M-CHAT-R ${ }^{\text {TM }}$ (Modified Checklist for Autism in Toddlers Revised)

Please answer these questions about your child. Keep in mind how your child usually behaves. If you have seen your child do the behavior a few times, but he or she does not usually do it, then please answer no. Please circle yes or no for every question. Thank you very much.

(FOR EXAMPLE, if you point at a toy or an animal, does your child look at the toy or animal?)

2. Have you ever wondered if your child might be deaf?

3. Does your child play pretend or make-believe? (FoR EXAMPLE, pretend to drink from an empty cup, pretend to talk on a phone, or pretend to feed a doll or stuffed animal?)

4. Does your child like climbing on things? (FOR EXAMPLE, furniture, playground equipment, or stairs)

5. Does your child make unusual finger movements near his or her eyes? (FOR EXAMPLE, does your child wiggle his or her fingers close to his or her eyes?)

6. Does your child point with one finger to ask for something or to get help? (FOR EXAMPLE, pointing to a snack or toy that is out of reach)

7. Does your child point with one finger to show you something interesting? (For EXAMPLE, pointing to an airplane in the sky or a big truck in the road)

8. Is your child interested in other children? (FoR EXAMPLE, does your child watch other children, smile at them, or go to them?)

9. Does your child show you things by bringing them to you or holding them up for you to see - not to get help, but just to share? (For EXAMPLE, showing you a flower, a stuffed animal, or a toy truck)

10. Does your child respond when you call his or her name? (FoR EXAMPLE, does he or she look up, talk or babble, or stop what he or she is doing when you call his or her name?)

11. When you smile at your child, does he or she smile back at you?

12. Does your child get upset by everyday noises? (FOR EXAMPLE, does your child scream or cry to noise such as a vacuum cleaner or loud music?)

13. Does your child walk?

14. Does your child look you in the eye when you are talking to him or her, playing with him or her, or dressing him or her?

15. Does your child try to copy what you do? (For EXAMPLE, wave bye-bye, clap, or make a funny noise when you do)

16. If you turn your head to look at something, does your child look around to see what you are looking at?

17. Does your child try to get you to watch him or her? (FoR EXAMPLE, does your child look at you for praise, or say "look" or "watch me"?)

18. Does your child understand when you tell him or her to do something? (FoR EXAMPLE, if you don't point, can your child understand "put the book on the chair" or "bring me the blanket"?)

19. If something new happens, does your child look at your face to see how you feel about it? (FoR EXAmPLe, if he or she hears a strange or funny noise, or sees a new toy, will he or she look at your face?)

20. Does your child like movement activities? (FOR EXAMPLE, being swung or bounced on your knee) э2 2009 Diana Robins, Deborah Fein, \& Marianne Barton

Figure $\mathbf{2 b}$ : The proposed combined Screening Tool of PSC and M-CHAT.

2. Suspects or observes any "Red Flag" signs in healthcare setting or community

3. Approaches the accompanying adult and establishes identity and carer responsibility, introducing oneself in a competent and professional ease

4. Applies "Breaking News" principles to broach upon the subject without provoking alarm
5. Competently achieves permission for appropriate referral; alternatively hands over information leaflet (which needs to be universally designed that says about why a healthcare professional might approach carer in such a manner and what they are supposed to do once they have "thought about it", informing them that soon somebody will make a follow up call in a week or two) for parents/carers to ponder about

6. A system of follow-up call is in-built (ideally the same 
Citation: Bhattacharya A (2014) Emotional/Educational, Behavioral \& Developmental [EBD] Problems in Children - Nursing Opportunities. Health Care Current Reviews 3: 132. doi: 10.4172/2375-4273.1000132

professional, if possible)

7. A failure to take up three such reminders should qualify for a Social Service referral under, perhaps 'unintentional neglect'!

8. Finally, the child is provided appropriate Early Intervention, nipping the ugly and hydra headed monster of downward spiral of such 'missed opportunity' through proactive and decisive prevention

9. Planners and Policy makers to ensure that such easy but robust preventative tool is put in place

10. Save 'Social Capital' before it sours off!

Such Universal Care Pathway for Preventing "Missed Opportunities" for Early Detection and Early Intervention is now long overdue!

\section{References}

1. Ibeziaco P, Shaw RJ, DeMasco DR. Psychosomatic Illnesses. Chapter 20 . Nelsons Textbook of Pediatrics. 19th Edition.

2. Wood BL (2001) Physically manifested illness in children and adolescents. A biobehavioral family approach. Child Adolesc Psychiatr Clin N Am 10: 543-562 viii.

3. Stafford B. Child and Adolescent Psychiatric Disorders and Psychosocial Aspects of Pediatrics. Chapter 6 Pediatrics. Diagnosis \& Treatment. McGraw Hill Publication. 2010. 1:172-177
4. DeSocio J, Hootman J (2004) Children's mental health and school success. J Sch Nurs 20: 189-196

5. O'Brien SH, Holubkov R, Reis EC (2004) Identification, evaluation, and management of obesity in an academic primary care center. Pediatrics 114 : e154-159.

6. Cookson R, Dolan P (2000) Principles of justice in health care rationing. J Med Ethics 26: 323-329.

7. McCrone P, Craig TK, Power P, Garety PA (2010) Cost-effectiveness of an early intervention service for people with psychosis. Br J Psychiatry 196: 377-382.

8. Back AL, Arnold RM, Baile WF, Fryer-Edwards KA, Alexander SC, et al. (2007) Efficacy of communication skills training for giving bad news and discussing transitions to palliative care. Arch Intern Med 167: 453-460.

9. Dubé CE, LaMonica A, Boyle W, Fuller B, Burkholder GJ (2003) Selfassessment of communication skills preparedness: adult versus pediatric skills. Ambul Pediatr 3: 137-141.

10. Wakefield A, Cooke S, Boggis C (2003) Learning together: use of simulated patients with nursing and medical students for breaking bad news. Int J Palliat Nurs 9: 32-38.

11. Whitehead NS, Brown DS, Layton CM (2010) Developing a Conjoint Analysis Survey of Parental Attitudes Regarding Voluntary Newborn Screening. RT Press publication No. MR-0014-1003. Research Triangle Park, NC: RT International.

12. Nelsons Textbook of Pediatrics. 19th Edition for Indian Subcontinent. P-59 